\title{
Field Investigation on Cystic Hydatid Infection in Camel in Tambool Town, Sudan
}

\author{
Ekram Ismail Fagiree Ismail* and Mesfer A Al-Thebaiti \\ Department of Biology, University of Hafr Al Batin, KSA
}

*Corresponding author: Ekram Ismail Fagiree Ismail, Department of Biology, Collage of Science, University of Hafr Al Batin, KSA.

To Cite This Article: Ekram Ismail Fagiree Ismail.Field Investigation on Cystic Hydatid Infection in Camel in Tambool Town, Sudan. Am J Biomed Sci \& Res. 2019 - 5(6). AJBSR.MS.ID.000971. DOI: 10.34297/AJBSR.2019.05.000971.

Received: 阱October 14, 2019; Published: 眥 October 22, 2019

\author{
Abstract \\ The aim of this study was to evaluate the prevalence of the disease in camels in Tambool area, Sudan with emphasis on the number and stages \\ of cysts in different organs. The investigation revealed $21.3 \%$ \\ prevalence rate among camels. \\ Keywords: Hydatidosis; Field investigation; Hydatid cyst; Sudan
}

\section{Introduction}

Echinococcosis or hydatidosis is a cyclozoonotic disease of worldwide importance caused by the closely related cestode parasites, Echinococcus granulosus and Echinococcus. Multilocularis [1]. The disease has a particularly high incidence in countries where the association between man, dog, and farm animals is close $[2,3]$ described the disease as a medical and to a lesser extent, an economic problem in the inhabited continents. Cystic echinococcosis (CE) is a zoonotic disease affecting various species of livestock and humans. It is distributed worldwide, acquiring public health or economic significance in areas where extensive livestock production provides suitable condition for the cyclic transmission between dogs and livestock animals. CE is considered an emerging neglected disease in many parts of the world; in some regions re-emerging after initially successful control [4,5]. Hydatidosis in camels was first reported in the Sudan in 1908 $[6,7]$ subsequently reported a high prevalence of the disease among camels especially in areas where they are slaughtered in large numbers, like Tambool area. Echinococosis or hydatidosis reported with economic zoonotic helmenthic disease of the tropic equatorial regions of the world [8].

\section{Materials and methods}

It is a cross-sectional study.

The field work was conducted in Tambool area (Central Eastern Sudan) where slaughtered camels were checked for hydatid cysts.
Laboratory work was performed at the laboratories of the Faculty of Education,

Alzaem Alazhari University and the Faculty of Education, University of Khartoum.

The study included camels slaughtered at Tambool market. One hundred fifty slaughtered camels in Tambool market were thoroughly inspected for the presence of hydatid cysts in different organs. Hydatid cysts, when found were counted. The size of the cysts was measured using an ordinary ruler. Aspiration of cyst fluid was made for detection of fertility or sterility status of the cysts.

For the size of hydatid cyst, four groups were categorized as follows:
A. Small (diameter below 2 centimeters).
B. Medium (2-6 centimeters).
C. Large (7-10 centimeters).
D. Very large (over 10 centimeters).

The status of the cyst fluid was evaluated visually by observing the consistency of the fluid. Accordingly, the fluid was described as clear (watery), turbid or caseated (cheese-like)

According to the stage of the cyst, cysts were divided into:

A. Fertile cyst (fluid with scoleces). 
B. Sterile cyst (clear fluid).

C. Under calcified cyst.

D. Fully calcified cyst.

Fertility of collected cysts was determined using the folowing:
One drop of each hydatid fluid was placed on glass slide and covered with cover slip. The slide was examined under the light microscope using the objective lens10x for the presence of the scoleces.

\section{Results}

\begin{tabular}{|c|c|c|c|c|c|}
\hline \multicolumn{1}{|c|}{ Table 1: Occurrence of hydatid cysts in slaughtered camels in Tambool area. } \\
\hline \multicolumn{3}{|c|}{ No of cyst per organ } \\
\hline No of slaughtered camels & No of infected camels & liver & Lung & spleen & total \\
\hline 150 & $32(21.3 \%)$ & $21(15.4 \%)$ & $114(83.8 \%)$ & $1(0.75 \%)$ & 136 \\
\hline
\end{tabular}

Out of a total of 150 heads of camels examined in Tambool area, $32(21.3 \%)$ were seen to be infected with hydatid cysts (Table1). The 32 infected camels showed 114 cysts in the lungs, 21 cysts in the liver and one in the spleen. The most frequent predilection site was the lung and then the liver. Cysts in the spleen were found only in one case.
Most cysts in both the lungs and livers were of the medium size (2-6 cm in diameter). 56 cysts in the lungs and 6 cysts in the liver were of the medium size. 52 cysts in the lungs and 15 cysts in the liver were of the small size (diameter below $2 \mathrm{~cm}$ ). 6 cysts were of the large size (diameter of $7-10 \mathrm{~cm}$ ) in the lungs while no large cyst in the liver was observed (Table 2, Figure 1\&2).

Table 2: Sizes of cysts encountered in organs of the infected camels.

\begin{tabular}{|c|c|c|c|c|c|c|c|c|c|c|c|c|}
\hline \multirow[t]{2}{*}{ predilection } & \multicolumn{3}{|c|}{$\begin{array}{c}\text { liver \& lung of same } \\
\text { animal }\end{array}$} & \multicolumn{3}{|c|}{ Only } & \multicolumn{3}{|c|}{ Total } & \multicolumn{3}{|c|}{ probability } \\
\hline & liver & lung & spleen & liver & lung & spleen & liver & lung & spleen & liver & lung & spleen \\
\hline Small $(<2 \mathrm{~cm})$ & 16 & 26 & 0 & 2 & 23 & 1 & 18 & 49 & 1 & 0.13 & 0.36 & 0.01 \\
\hline Medium $(2-6 \mathrm{~cm})$ & 3 & 9 & 0 & 0 & 48 & 0 & 3 & 57 & 0 & 0.02 & 0.43 & 0 \\
\hline Large $(6-10 \mathrm{~cm})$ & 0 & 2 & 0 & 0 & 4 & 0 & 0 & 6 & 0 & $\mathbf{0}$ & 0.05 & $\mathbf{0}$ \\
\hline V. large $(>10 \mathrm{~cm})$ & 0 & 0 & 0 & 0 & 0 & 0 & 0 & 0 & 0 & 0 & 0 & 0 \\
\hline
\end{tabular}

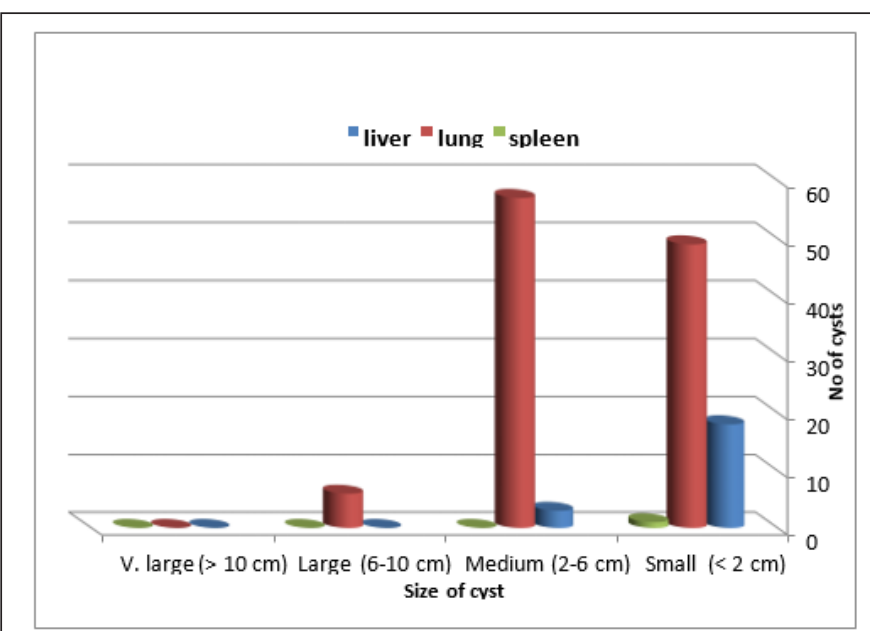

Figure 1: Sizes of cysts encountered in organs of the infected camels.

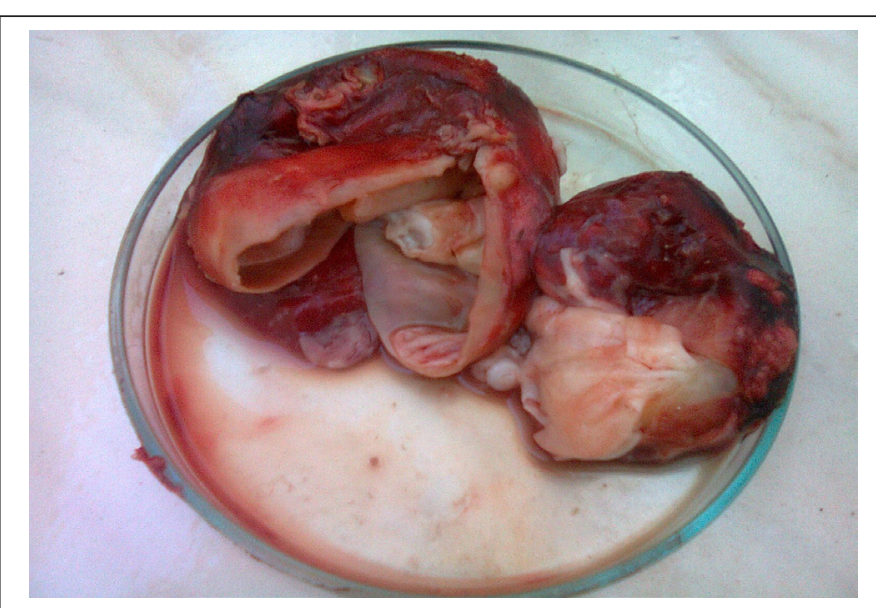

Figure 2: Cysts in a lung (right) and a liver (left) obtained from the infected camels. 
The number of fertile cysts in the lungs was greater than that in the livers and the number of cysts filled with fluid (fertile and sterile) is greater in lungs than in the livers (Figure 3). Many cysts in the liver were sterile (14 out of 21). Cysts under calcification were found only in the lungs while fully calcified cysts were found in both lungs and livers (Table 3, Figure 4).

\begin{tabular}{|c|c|c|c|c|c|c|c|c|c|c|c|c|c|}
\hline \multirow{2}{*}{$\begin{array}{l}\text { Predilection sites ir } \\
\text { different } \\
\text { organ Stages of } \\
\text { cyst }\end{array}$} & \multicolumn{4}{|c|}{$\begin{array}{l}\text { liver \& lung of } \\
\text { same animal }\end{array}$} & \multicolumn{3}{|c|}{ only } & \multicolumn{3}{|c|}{ total } & \multicolumn{3}{|c|}{ probability } \\
\hline & liver & lu & & spleen & liver & lung & spleen & liver & lung & spleen & liver & lung & spleen \\
\hline Fertile & 4 & 6 & & 0 & 0 & 36 & 0 & 4 & 99 & 0 & 0.03 & 0.7 & 0 \\
\hline Sterile & 14 & 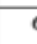 & & 0 & 0 & 7 & 0 & 14 & 13 & o & 0.1 & 0.1 & o \\
\hline $\begin{array}{c}\text { Under } \\
\text { calcification }\end{array}$ & o & 3 & & o & o & 4 & o & o & 7 & $\mathbf{o}$ & o & 0.04 & o \\
\hline Fully calcified & 3 & . & & 1 & 0 & 0 & 0 & 3 & 1 & 1 & 0.02 & 0.01 & 0.01 \\
\hline
\end{tabular}

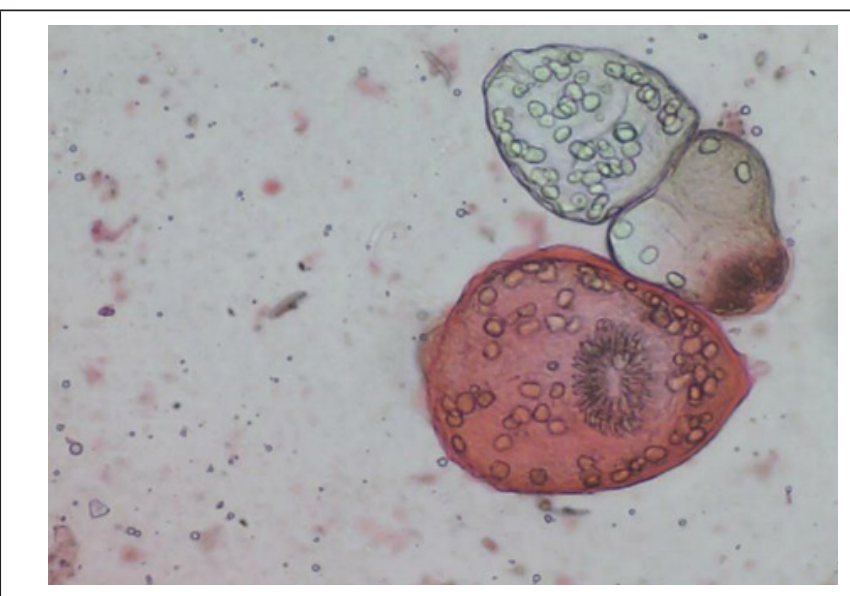

Figure 3: Protoscoleces in a lung obtained from the infected camels.

The pattern of livers and lungs with one cyst each was similar as 3 lungs were seen with one cyst and 12 livers as well. In organ with 2-4 cysts, the picture was different. 20 lungs and 6 livers were

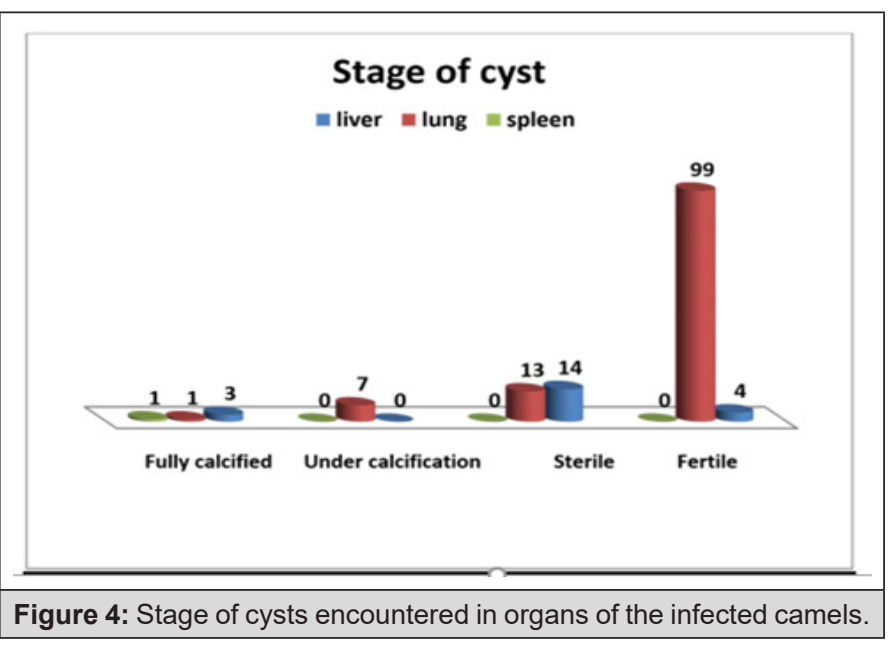

observed. Organ with 5-10 cysts was seen in 9 lungs. The only spleen that was affected had only one cyst (Table 4, Figure 5).

\begin{tabular}{|c|c|c|c|c|c|c|c|c|c|c|c|c|}
\hline \multirow{2}{*}{$\begin{array}{l}\text { Predilection sites } \\
\text { in different }\end{array}$} & \multicolumn{3}{|c|}{$\begin{array}{l}\text { Liver \& Lung of } \\
\text { same animal }\end{array}$} & \multicolumn{3}{|c|}{ Only } & \multicolumn{3}{|c|}{ Total } & \multicolumn{3}{|c|}{ Probability } \\
\hline & liver & lun: & spleen & liver & Lung & spleen & liver & lung & spleen & liver & lung & Spleen \\
\hline 1 & 12 & 1 & 0 & 0 & 2 & 1 & 12 & 3 & 1 & 0.24 & 0.1 & 0.02 \\
\hline $2-4$ & 4 & 8 & 0 & 2 & 12 & 0 & 6 & 20 & 0 & 0.12 & 0.4 & 0 \\
\hline $5 \cdot 10$ & 0 & 7 & 0 & 0 & 2 & 0 & 0 & 9 & 0 & 0 & 0.2 & 0 \\
\hline over 10 & 0 & 0 & 0 & 0 & 0 & 0 & 0 & 0 & 0 & 0 & 0 & 0 \\
\hline
\end{tabular}




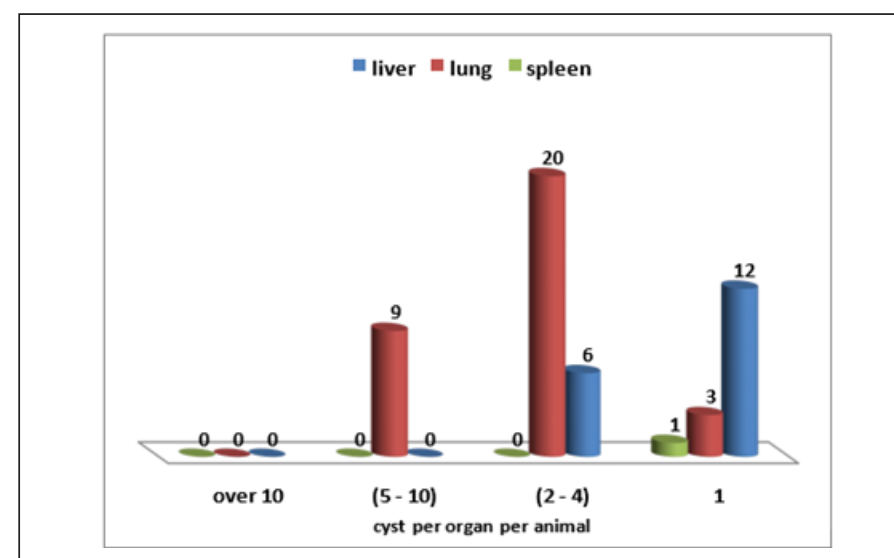

Figure 5: Cyst per organ per animal encountered in organs of the infected camels.

\section{Discussion}

Distribution map of hydatid disease like that described by Cameron and Webster [9], suggests that the disease is rare or absent over much of tropical Africa. But, as shown in Table 1, it is obvious that, far from being rare, hydatid disease in domestic animals in the Sudan as part of tropical Africa is more prevalent .This agrees with the findings of French and $[10,11]$ who described fully this serious problem among the Turkana tribe in northern Kenya .The seriousness of infection among man and animals (both domestic and wild) in that part of Africa justified the establishment of a hydatid research unit in the area.

In the present study, 150 camels were examined at meat inspection. The overall prevalence rate of hydatidosis in Sudan varies with the variations of the number of animals slaughtered in different part of the country. As shown before, cattle and sheep are slaughtered in all areas investigated. Camels are slaughtered in relatively large numbers in Tambool and Elfasher. Goats are not favored in most of the areas investigated; therefore, the number of goats examined was comparatively small, but it is hoped to give a representative profile for measuring the prevalence and fertility of hydatid cysts.

In the investigation of [12], only two fertile cysts were observed in sheep. All other cysts detected were calcified or under calcification. This may be since sheep brought to legal slaughter are rather old; younger ones usually kept for illegitimate slaughter.

Investigation of the disease in camels revealed that at Tambool, $43.9 \%$ of the carcases examined were infected, size of cyst was shown to reach up to $9.5 \mathrm{~cm}$ and its fertility rate was high. Infrequently, some organs were found to be heavily infected. For example, 26 cysts were encountered in one lang. This may ascertain the important role of camels in the cycle of the parasite as previously mentioned by [12].

The fertility rate encountered in cysts for different animals showed the camel cysts to have the highest rate $(37.3 \%)$ and sheep the lowest $(0.6 \%)$. This finding is consistent with [1] who observed high fertility rate of camel's cysts in Egypt. Surprisingly, fertility rate of cysts recovered from cattle was exceptionally high (29\%) which differs [1] who found the lowest rate of fertility (11.3\%) in cattle in Egypt. Our finding is not in line with [13] who stated that " the cysts may fail to form scoleces in $90 \%$ of cattle". However, high fertility rate of cattle cysts was reported by $[14,15]$ attributed this high fertility rate to an unusual strain of E. granulosus.

In camels, the cysts are mostly found in the lungs and rate of fertility of the lung cysts is very high while in cattle and sheep the cysts are mostly located in the liver.

In some parts of the Sudan, because of the dry and warm climate, camels constitute domestic animal and livestock found in close contact with dogs which might explain such high prevalence of hydatid cysts in camels. Because animals have more chances in contact with infected dogs, it is not surprising to find higher infection among them. Despite that the camel is considered a browsing animal, the high infection arte in Tambool area may be explained by the fact that camels feed on "Nal" (grasses used for roofing rooms in rural areas). This "Nal" is subject to contamination with dog feces. Another reason justifying this high infection is that the nomads after slaughtering a camel throw all the organs except the liver to their dogs. Thus, helping in the transmission of the infection. When nomads settle somewhere, they keep their dogs with their camels at the same place. Thus, disseminating the infection to their own camels.

As mentioned by [12], the importance of camels in the cycle of the parasite has been proven in Egypt where [16] considered them to be the top reservoir hosts of infection in Egypt and buffaloes comes in second order. According to Saad [12] findings, it is thus apparent that camels and cattle throughout Sudan are commonly infected with hydatid cysts and that as far as the data collected is concerned, they are the major intermediate host which transmit the infection to the definitive and the disease passes either directly or indirectly to man.

As has been shown in the result, calcified and under calcified cysts were mentioned. In fact, these cysts may be important in defining the prevalence quantitatively but, they will not have any impact in the life cycle and epidemiology of the disease. As far as the epidemiology of the disease is concerned, one may be interested in the proportion of the infected population that carry fertile cysts and can therefore play an important role in the transmission of the disease. These results agreed with those shown by [12].

Our finding that the lungs of camels were found to be more commonly infected with hydatid cyst than the livers is in agreement with a previous finding of [17] Ibrahim and Craig [22].This might be due to the fact that camels are slaughtered at older age, during which period the liver capillaries are dilated and most oncosphere passed directly to the lungs; additionally it is possible to the Echinococcus oncosphere to enter the lymphatic circulation and be 
carried via the thoracic duct to the heart and the lung in such a way that the lung may be infected before or instead of liver as observed by [18].

overall percentage of fertile cyst in this study was $96.1 \%$ in the lungs. Various surveys throughout the country have indicated that high cyst fertility rate is commonly found in camel $[5,15,20,21,25]$ hence, they are potential sources of infection to dogs. The difference in fertility and the proportion of variable protoscoleces from fertile cyst may be related to the difference in immunological response per host, Moreover, the fertility of hydatid cysts in the intermediate hosts may be also genotype dependent [19].

In comparison of the fertility rate among the organs, it was higher in lungs than livers and spleen. It has been stated that the relatively softer consistency of lung tissue allows the easier development of the cyst [20] whilst the viability rate of protoscoleces of liver fertile cysts was significantly higher than that of lung cyst and spleen ones, respectively. This agrees to the finding of [17] in camels slaughtered in Iran. He reported that the fertility of cyst in the lung (69.7\%) of camels in Iran was higher than that in the liver $(58.7 \%)$ and spleen (50\%). Whilst the viability rate of liver fertile cysts (80.3\%) was higher than that of lung (55.8\%). Furthermore, the greater prevalence and higher fertility rate of pulmonary cysts over hepatic cysts of camel indicate the importance of each internal organ as a potential source of infection to dogs. In E. granulosus endemic areas of Iran, it is evident that, the majority of E. granulosus infected livestock animals can potentially act as reservoirs of human infection [21-27].

\section{References}

1. El Kordy MI (1946) On the incidence of hydatid disease in domestic animals E. granulosus protoscoleces in Egypt. Egypt Med Assoc 29 Parasitol Int 57: 185-190.

2. Gibson TE (1969) Biology of hydatidosis. Vet. Rec. 85: 320-322.

3. Schwabe CW (1968) Epidemiology of echinococcosis in the Middle East. I Human (1949-1959). Am J Trop Med Hyg 10(3): 374-381.

4. Eckert J, Gemmell MA, Meslin FX and Pawlowski ZS (2001) Echinococcus granulosus and related species with emphasis on their infectivity to humans. Acta Trop 64: 19-34.

5. Jenkins DJ, MD Rickard (2005) Hematological and serological data from dogs raised worm-free and mono specifically infected with helminths. Aust Vet J 61: 309-311.

6. Annon (1908) Annual reports of the Ministry of Animal Resources, Khartoum, Sudan.

7. Saad MB (1983) The survival rate of protoscolices from hydatid fluid kept at constant temperatures. Sudan J Vet Res (4)157.

8. Salwa PI, Alhindy H, Najla A (1980) Enzyme immune essay in helminthes infection with special reference to: schistosomiasis, fasciolasis, trichnelasis and hydatidosis. Thesis, Cairo University, Egypt.
9. Cameron TWM, Webster GA (1969) The histogenesis of the hydatid cyst (Echinococcus spp.) Part 1. Liver cysts in large mammals. Canadian Journal of Zoology 47(6): 1405-1410.

10. French CM, Nelson GS, Wood M (1982) Hydatid disease in Turkana District of Kenya. I. The background to the problem with hypothesis to account for the remarkably high prevalence of the disease in man. Ann. Trop Med Parasit 76(4): 425-437.

11. French CM, Nelson GS (1982) Hydatid disease in Turkana District of Kenya. II.A study in medical geography. Ann Trop Med Parasit 76(4): 439-457.

12. Saad MB (1985) Hydatidosis/Echinococcosis in the Sudan with Emphasis on the Epidemiology, Experimental Transmission and Histopathology. University of Khartoum, Sudan.

13. Lapage G (1968) “Veterinary Parasitology” $2^{\text {nd }}$ ed. Oliver and Boyd P 432.

14. Froyd G (1960) The incidence of liver fluke (Fasciola gigantic) and hydatid cyst (Echinococcus granulosus) in Kenya cattle J Parasit 46: 659-662.

15. Nelson GS, Rausch RL (1963) Echinococcosis infection in man and animals in Kenya. Ann Trop Med parasite 57: 136-149.

16. Halawany A (1956) Hydatid disease in Egypt. Archos. Int Hydatid 15(122): 374-375.

17. Ahmadi NA (2005) Hydatidosis in camel (Camelus dromedaries) and their potential role in the epidemiology of Echinococcus, granulosusu. Iran J Helminthol 79: 119-125

18. Ragassa F, Mola A, Bekele J (2010) A study of prevalence of cystic echinococcosis. pp. 977-984.

19. McManus DP, Zhang W, Li J, Bartley PB (2003) Echinococcosis. The Lancet 362: 1295-1305

20. Himanos C (1987) The fertility of hydatid cyst in the food animals in Greece. Helminth. Zoonoses Sci Parasitol 12(2): 77-83.

21. Daryani A, Sharif M, Amouei A, Nasrolahei M (2009) Fertility and viability rates of hydatid cycts in slaughtered animals in the Mazandaran Province, Northern Iran. Trop Anim Health Prod 41(8): 1701-1705.

22. Craig PS, McManus DP, Lightowlers MW, Chabalgoity JA, Garcia HH, et al. (2007) Prevention and control of cystic echinococcosis. The Lancet $7(6): 385-395$.

23. Dalimi A, Motamedi G, Hosseini M, Mohammadain P, Malaki H, et al. (2002) Echinococcosis/hydatidosis in Western Iran. Vet Parasitol 105(2): 161-171.

24. Hoseini SH, Eslam A (1998) Morphological developmental characteristics of E. grannlosus derived from sheep, cattle and camels in Iran. J Helmithol 72(4): 337-341.

25. Matossian RM, Rickard MD, Smyth JD (1977) Hydatidosis: a global problem of increasing importance. Bull World Health Organ 55(4): 499507.

26. Mobedi I, Madadi H, Arfaa F (1970) Camel, camelus dromedaries as intermediate host of Echinococcus granulosus in Iran. J Parasit 56(6): 1255.

27. Moghader N, Oryan A, Hanifpour MR (1992) Helimenth recovered from the liver and lung of camels with special reference to the irincidence and pathogenethis in Shiraz. Islamic Republic of Iran. Indian J Anim Sci 62: 1018-1023. 